\title{
Erythema a computatro
}

\author{
G.G. Gauglitz T. Ruzicka T. Herzinger \\ Department of Dermatology and Allergy, Ludwig-Maximilian University, Munich, Germany
}

\section{Key Words}

Erythema ab igne $\cdot$ Laptop $\cdot$ Heating

\begin{abstract}
Historically, erythema ab igne (EAI) was commonly seen on the shins of individuals working in front of coal stoves or sitting close to a fireplace. In the more recent past, this condition has been primarily observed after repeated application of heating pads. Today, unintentional and unperceived exposure to heat from laptop computers needs to be considered as a potential trigger. A rising number of laptop-induced cases of EAI have been reported recently. For this modern-age version of classic EAI, we propose thus the more accurate neoLatin term erythema a computatro.
\end{abstract}

\section{Case Presentation}

A 36-year-old woman presented with a history of asymptomatic patches on her legs. Physical examination revealed reticulated, reddish-brown macules with an ill-defined border on the anterior aspect of both thighs (fig. 1). The patient denied prolonged contact with any heat sources. Upon detailed questioning, she eventually recalled having worked with a laptop computer on her thighs for approximately $1 \mathrm{~h}$ every day over the past 18 months (fig. 2).

\section{Discussion}

Similar skin changes are known as erythema ab igne (EAI, erythema from fire) after chronic exposure to subliminal levels of infrared radiation insufficient to cause burns. The typical reticulated erythema initially appears reddish, and gradually turns brownish due to increased pigmentation. Microscopic changes of EAI include hyperkeratosis, epidermal

Gerd G. Gauglitz, MD

Department of Dermatology and Allergy, Ludwig-Maximilian University

Frauenlobstrasse 9-11

DE-80337 München (Germany)

E-Mail Gerd.Gauglitz@med.uni-muenchen.de 
Gauglitz et al.: Erythema a computatro

atrophy, squamous atypia, and interface dermatitis with necrotic keratinocytes [1, 2]. An accumulation of dermal elastotic tissue, which represents an early sign of both UV radiationand heat-induced skin damage, may also be seen [3]. Rare cases of squamous cell carcinoma and Merkel cell carcinoma arising in lesions of EAI have been reported [4]. EAI has thus been considered a precancerous lesion. No effective treatment is available. Progression of the disease can only be halted by the avoidance of further heat exposure.

Historically, EAI was commonly seen on the shins of individuals working in front of coal stoves or sitting close to a fireplace. Overall, the incidence of classic EAI has decreased since the introduction of central heating. Localization of the lesions corresponds to the different sources of heat that are currently in use. In the more recent past, they were primarily observed after repeated application of heating pads. A car heater and heating blankets are other reported sources of EAI. Today, unintentional and unperceived exposure to heat from laptop computers needs to be considered as a potential trigger. For this modern-age version of classic EAI, we propose the more accurate neo-Latin term erythema a computatro. A rising number of laptop-induced cases of erythema a computatro have been reported recently [5]. Our case is particular in that lesions occurred on both thighs. Most cases were induced by heat radiating from the optical drives of the laptops and thus involved only one leg.

The rising incidence of erythema a computatro requires physicians to be aware of the clinical significance of unintentional heat exposure through laptop computers. Laptop users should be alerted to this condition and abstain from placing laptops on top of their lap for prolonged periods of time.

\section{Acknowledgements}

The authors would like to thank Dr. K.A. Neuhausen, University of Bonn, Germany, for expert advice on neo-Latin terminology.

\section{Disclosure Statement}

The authors declare that they have no financial and personal relationships with other people or organizations that could inappropriately influence this work.

\section{References}

1 Shahrad P, Marks R: The wages of warmth: changes in erythema ab igne. Br J Dermatol 1977;97:179-186.

-2 Arrington JH 3rd, Lockman DS: Thermal keratoses and squamous cell carcinoma in situ associated with erythema ab igne. Arch Dermatol 1979;115:1226-1228.

3 Johnson WC, Butterworth T: Erythema ab igne elastosis. Arch Dermatol 1971;104:128-131.

4 Peterkin GA: Malignant change in erythema ab igne. Br Med J 1955;31:1599-1602.

5 Arnold AW, Itin PH: Laptop computer-induced erythema ab igne in a child and review of the literature. Pediatrics 2010;126:e1227-e1230. 


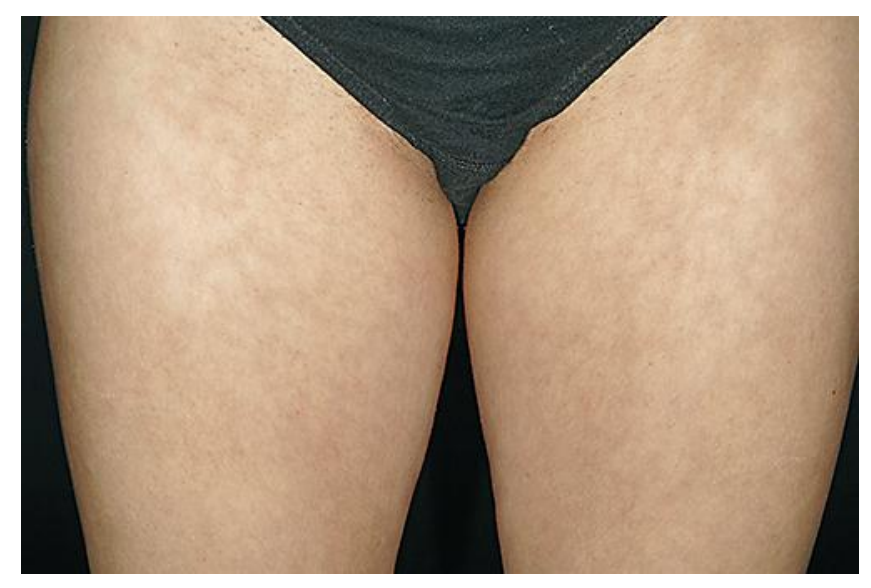

Fig. 1. Erythema a computatro on the anterior aspect of the thighs characterized by reticulated, reddishbrown pigmented patches with ill-defined borders.

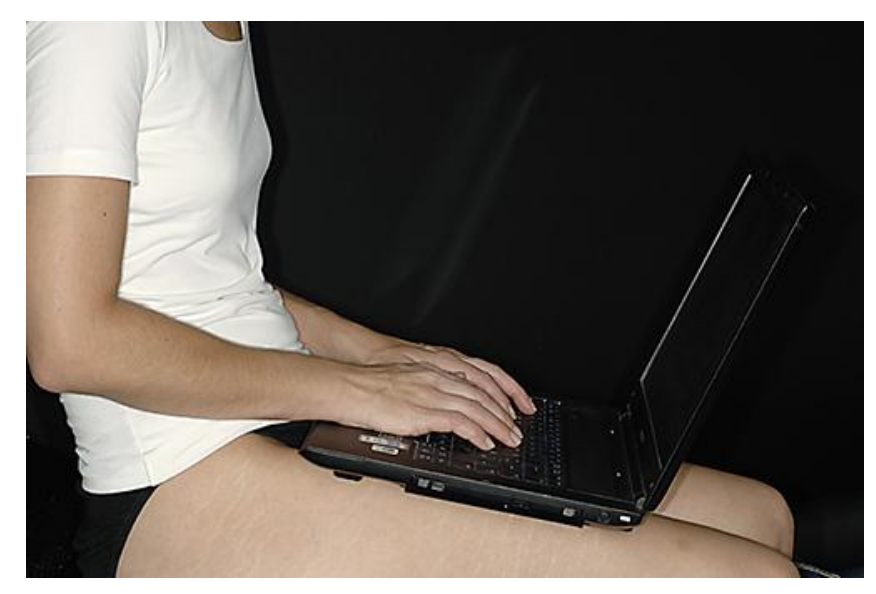

Fig. 2. The patient working with a laptop computer on her thighs. 